\title{
Matching the rate of concurrent tone bursts and light flashes as a function of flash surround luminance
}

\author{
ARLO K. MYERS, BILL COTTON, and HARRY A. HILP \\ University of California, Riverside, California 92521
}

\begin{abstract}
Subjects adjusted the rate of a repeating toneburst to match that of a concurrently flashing light, or vice versa. Flashes were viewed in luminous or wholly dark surrounds. Matches usually departed from veridical rate matches, and always were affected in the same direction by changes in surround luminance. Matches were a function of whether subjects controlled the visual or auditory stimulus; also, subjects usually reported "driving" of flash rates by auditory rates when they controlled tone rate, but not when they controlled flash rate.
\end{abstract}

When an observer views a repeatedly flashing light and simultaneously hears a repeated clicking sound at repetition rates around 4-10 $\mathrm{Hz}$, the apparent rates of the auditory and visual stimuli may appear markedly different from each other, even when the flash and click rates are identical and are produced in synchrony by means of a single pulse-train generator. While making informal observations of this effect, the authors noted that the apparent rate of the flashes instantaneously increased when the room in which they were viewed was darkened, and decreased again when lights were restored. These effects were duplicated in pilot studies in which subjects matched the rate of a flashing light by adjusting the rate of an independently variable clicking sound.

There are a number of studies in the literature that deal with the apparent rate or frequency of repetitive visual and/or auditory stimuli (Forsyth \& Chapanis, 1958; Garner, 1951; Lechelt, 1975; Mackavey, 1966; Massaro, 1976; Pollack, 1952; Springer, Deutsch, \& Stanley, 1975; Stevens \& Shickman, 1959; Taubman, 1950a, 1950b; White \& Cheatham, 1959). There are a few studies in which subjects matched continuously repeating flashes and sounds presented simultaneously, as done in the present study (Gebhard \& Mowbray, 1959; Nelson, Bartley, \& Bochniak, 1965; Segal, 1940).

We know of no previous studies that have investigated apparent visual repetition rate as a function of the luminance of the surrounds of the target stimulus, though there have been some that varied the luminance of the target stimulus itself (Mackavey,

Supported in part by a research grant from the Academic Senate, University of California, Riverside. We thank Diane Halpern for useful comments on an earlier draft of this paper. Bill Cotton's present address is Bell Laboratories, Room 3D-507A, Holmdel, New Jersey 07733. Address reprint requests to Arlo K. Myers, Department of Psychology, University of California, Riverside, California 92521.
1966; Nelson, Bartley, \& Bochniak, 1965; Segal, 1940). The present experiments provide some interesting comparisons with the stimulus luminance effects reported in those studies. There are also some instructive similarities and differences between our results and the results of previous studies with regard to (1) the disparity in actual rate of auditory and visual stimuli that are judged to be matched (Gebhard \& Mowbray, 1959; Nelson, Bartley \& Bochniak, 1965; Segal, 1940), (2) reports of modal interaction in which the rate of an auditory stimulus appears to control or "drive" the rate of visual flashes (Gebhard \& Mowbray, 1959), (3) significant differences in matching performance as a function of whether the subject controls or adjusts the auditory or the visual stimulus (Gebhard \& Mowbray, 1959), and (4) the on-off ratio or duty cycle of the visual stimulus (Gebhard \& Mowbray, 1959; Nelson, Bartley, \& Bochniak, 1965).

\section{EXPERIMENT 1}

Subjects viewed a red light-emitting diode (LED) flashing continuously at 4,7 , or $10 \mathrm{~Hz}$ and adjusted the rate of a continuously variable repeating toneburst, heard through headphones, until the rates of the two stimuli appeared matched. The LED was viewed either in wholly dark surrounds or centered in an illuminated white surround field. Two different on/off ratios of the visual stimulus were studied. The LED was operated at a relatively low luminance $\left(52 \mathrm{~cd} / \mathrm{m}^{2}\right)$ for the first 10 subjects. After reports that the LED was difficult to judge against the illuminated surround at this intensity, its luminance was increased to $340 \mathrm{~cd} / \mathrm{m}^{2}$, and 30 subjects were tested with this brighter flash stimulus. The first 10 subjects are treated in the results as supplementary comparison for flash-intensity effects. 


\section{Method}

Subjects. Forty students from an introductory psychology class at the University of California, Riverside, served as subjects to fulfill a course requirement. The subjects were screened for normal hearing and normal or corrected-to-normal vision.

Apparatus. The visual display consisted of a 5-mm-diam red LED centered in a diffuse white annular surround $30 \mathrm{~cm}$ in diameter. The LED had a dominant wavelength of approximately $650 \mathrm{~nm}$. In the main experiment (30 subjects), the LED's luminance was $340 \mathrm{~cd} / \mathrm{m}^{2}$; in the supplementary group (10 subjects), its luminance was $52 \mathrm{~cd} / \mathrm{m}^{2}$. The surround employed a white fluorescent back-lighting system which, when lighted, produced a luminance of $215 \mathrm{~cd} / \mathrm{m}^{2}$.

The LED flashed at a rate of 4,7 , or $10 \mathrm{~Hz}$. There were two flash durations: short, in which each flash was $25 \mathrm{msec}$ of light, and long, in which each flash was a $25-\mathrm{msec}$ extinction of the otherwise lighted LED. Twenty-five millisecond bursts of a 1,500$\mathrm{Hz}$ tone at $87 \mathrm{~dB}$ SPL were presented via headphones at a rate that was adjustable by the subject over a continuous range from 1.5 to $32 \mathrm{~Hz}$. The repetition rate of either the visual or auditory stimulus could be read out on an electronic tachometer.

Procedure. The subject's task was to adjust the repetition rate of the toneburst so as to match the fixed flash rate being presented simultaneously on a given trial. Flashes were observed in free binocular view. At the nominal distance of $76 \mathrm{~cm}$, the LED subtended a visual angle of $.75 \mathrm{deg}$, and its surround, $22.3 \mathrm{deg}$. After two practice trials, each subject was given a randomized sequence of 24 trials. On half of these trials, the LED was viewed in complete darkness. On the other half, the annular surround was illuminated. Each subject received four trials at each of the six combinations of three flash rates and two surround conditions (i.e., surround on or surround off). On a random half of the trials, the to-be-adjusted toneburst was set initially at the high end of the rate scale; on the other half, it was set at the low end. Half the subjects were assigned randomly to the short flash condition; the remainder were assigned to the long flash condition.

The instructions encouraged the subjects to use a bracketing procedure to get the best possible rate match. Each trial was terminated by a verbal "OK" from the subject, and during the brief intertrial interval, the stimuli were switched off and the room was dimly illuminated. At the end of the experimental session, the subjects were asked to give their subjective impressions of the matching task, and then were debriefed.

\section{Results}

The results are displayed in the two top panels of Figure 1. Since there were no reliable effects whatever of short vs. long flash duration, data from both are combined in the figure. The 30 subjects that had the $340-\mathrm{cd} / \mathrm{m}^{2}$ flash intensity and the 10 that had the $52-\mathrm{cd} / \mathrm{m}^{2}$ intensity were analyzed separately. For the main experiment with the $340-\mathrm{cd} / \mathrm{m}^{2}$ flash, the mean matching toneburst rate was a highly reliable function of the three different flash rates being matched $(p<.001)$. It was very reliably greater for the dark than for the lighted surround $(p<.001)$. There was a reliable interaction between flash rate and surround luminance $(p<.05)$, with the effect of dark vs. lighted surround being somewhat greater at $7 \mathrm{~Hz}$ than at 4 or $10 \mathrm{~Hz}$. The increase in matching toneburst rate with dark vs. lighted surround was $45 \%$ at $4 \mathrm{~Hz}$, $53 \%$ at $7 \mathrm{~Hz}$, and $21 \%$ at $10 \mathrm{~Hz}$. There was also a small but highly reliable effect of whether the initial toneburst rate was set high or low for the subject before a match was made $(p<.001)$; high initial set-
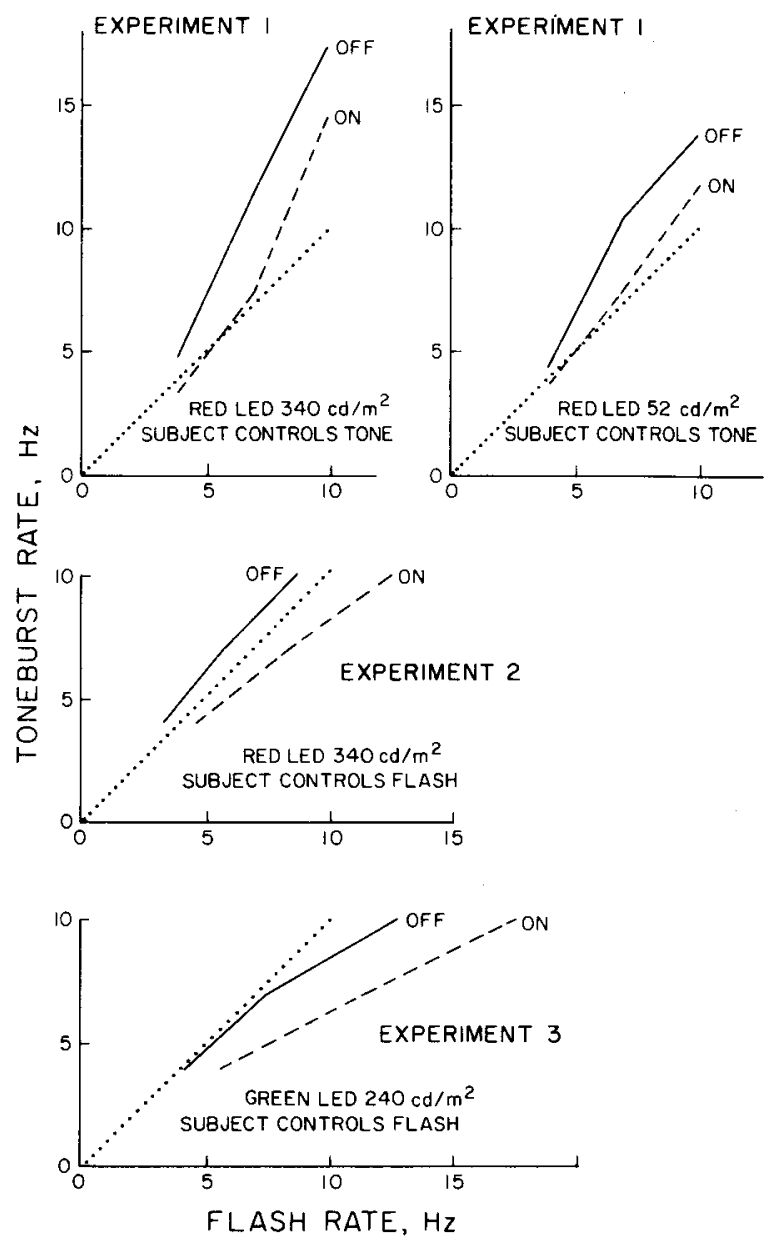

Figure 1. Average matches made between toneburst rates and flash rates in the groups of Experiments 1, 2, and 3. The linear diagonals through zero, zero intercept correspond to veridical rate matches. ON and OFF designate illuminated vs. dark surrounds for the flash stimulus.

tings resulted in slightly higher final match rate settings, and vice versa.

Similar results were obtained from the 10 subjects that had the $52 \mathrm{~cd} / \mathrm{m}^{2}$ flash intensity. There were highly reliable differences among the three flash rates $(\mathrm{p}<.001)$; matches were reliably greater for the dark than for the lighted surround $(p<.025)$, but the interaction between flash rate and surround luminance was not significant $(F<1.0)$. The overall increase in matched rate with dark vs. lighted surround was $25 \%$. Effects of initial toneburst rate setting were not analyzed for these data.

The subjects' settings generally tended to be much higher than an objective rate match, with this effect being greatest at the $10-\mathrm{Hz}$ flash rate and the brighter flash luminance. The most extreme deviation from a veridical match occurred with the brighter flash luminance, $10-\mathrm{Hz}$ rate, and dark surrounds, in which case the average toneburst rate selected was fully $72 \%$ higher than the flash being matched. 
Finally, $80 \%$ of the subjects in this experiment volunteered the information that the flash rate appeared to be "driven" by the toneburst rate; that is, within limits, the flash rate seemed to change so as to follow the variations in toneburst rate being produced by the subject in the process of matching.

\section{EXPERIMENT 2}

Gebhard and Mowbray (1959), using a matching procedure similar to that used in Experiment 1, also reported that auditory pulses seemed to "drive" visual flashes. However, when the matching task was reversed, that is, when the subject's task was to match the variable repetition rate of a flash to the fixed rate of a toneburst, no comparable effect was observed.

In Experiment 2, we reversed the procedure and had subjects match the flash to the toneburst in order to determine if subjective reports of "driving" still would occur, to see if variability of matching performance would be reduced, and finally, to further establish the generality of the surround luminance effect.

\section{Method}

Sixteen subjects from the same subject pool used in Experiment 1 participated, and the procedure was identical with that of Experiment 1, with the following two exceptions: (1) Since the duration of individual flashes produced no effects whatever in Experiment 1, all subjects were run in the short-flash condition, in which each flash consisted of $25 \mathrm{msec}$ of light from the red LED. The LED was operated at a luminance of $340 \mathrm{~cd} / \mathrm{m}^{2}$ throughout Experiment 2. (2) Each subject was presented with fixed toneburst rates of 4,7 , and $10 \mathrm{~Hz}$, and had to adjust the flash rate so as to match the toneburst rate-just the reverse of the matching task of Experiment 1.

\section{Results}

The results are shown in the middle panel of Figure 1. For purposes of comparison with Experiment 1 , toneburst rate still is scaled on the ordinate and flash rate on the abscissa, although flash rate was the dependent variable in this experiment.

The mean matched flash rate was a highly reliable function of the three different tone rates being matched $(p<.001)$. Again, the rate selected was a highly reliable function of whether the flashes were viewed in dark or luminous surrounds $(p<.001)$. The direction of this effect was the same as in the first experiment and comparable in magnitude: The flash rate matches made at 4-, 7-, and $10-\mathrm{Hz}$ tone rates were larger by $40 \%, 42 \%$, and $42 \%$, respectively, when the flashes were viewed in luminous rather than in dark surrounds. There was a reliable interaction between tone rate and surround condition $(p<.05)$. And, whereas $80 \%$ of the subjects in the first experiment reported "driving" of the visual stimulus by the auditory one, only 2 of $16,12.5 \%$, reported any driving effects in this second study, in which subjects adjusted the flash rate. This difference was highly reliable $\left[\chi^{2}(1)=16.68, p<.0002\right]$.
The subjects reported that matches were made with much greater ease and confidence with the present matching task, compared with that of Experiment 1. We therefore checked to see if there was a consistent difference in the variability with which matches were made in the two procedures. The data from each of the 12 experimental conditions of Experiment 2 (3 flash rates $\times 2$ surround conditions $\times 2$ initial rate settings) was compared with those of the corresponding experimental subgroup for those subjects in Experiment 1 who also had the $340-\mathrm{cd} / \mathrm{m}^{2}$ flash stimulus. The standard deviation of matches in this task tends to be linearly proportional to the mean, and the two matching tasks exhibited systematic differences in means. ${ }^{1}$ Therefore, instead of comparing the standard deviations of the subgroups, we compared the ratio of the standard deviation to the mean $(\sigma / \bar{X})$, known as the coefficient of variation (Huntsberger, $1967, \mathrm{p} .58$ ). This index is substantially independent of differences in mean performance in our data. Although the coefficient of variation did tend to be somewhat smaller in the subgroups of Experiment 2 than in the corresponding subgroups of Experiment 1, the difference was not statistically reliable $(p=.054$, one-tail, binomial sign test).

\section{EXPERIMENT 3}

A study by Springer, Deutsch, and Stanley (1975) indicates that under certain viewing conditions, apparent flash rate may be influenced by the wavelength of the stimulus. In Experiment 3, we sought to determine if the effects we were investigating could be affected by the hue of the LED. A yellow-green LED, hereafter called the "green" LED, was used as the visual stimulus.

\section{Method}

The subjects were 16 paid University of California students screened for normal hearing and normal or corrected-to-normal vision. A 5-mm-diam LED with a dominant wavelength of approximately $568 \mathrm{~nm}$ and a luminance of $240 \mathrm{~cd} / \mathrm{m}^{2}$ was substituted for the red LED. The apparatus would not permit raising the luminance of the green LED to the $340 \mathrm{~cd} / \mathrm{m}^{2}$ level used in Experiment 2 , so the flash stimulus differed both in luminance and wavelength from the red LED in the previous experiment. The luminance was, however, midway between the two red LED luminances employed in the two different groups of Experiment 1.

The procedure of Experiment 3 was identical to that of Experiment 2 .

\section{Results}

The results are displayed in the bottom panel of Figure 1, with tone rate again on the ordinate and flash rate on the abscissa, for ease of comparison with the other figures. The general pattern and magnitude of effects are the same as those in the previous experiment, with the exceptions noted below. The mean matched flash rate was once again a highly reliable function both of the tone rate to be matched $(p<.001)$ and of the surround luminance $(p<.001)$. 
When the surround was on, mean matches at 4,7 , and $10 \mathrm{~Hz}$ were $38 \%, 56 \%$, and $36 \%$ higher, respectively, than mean match performance with the surround off. There was a reliable Rate by Surround interaction $(p<.01)$ and a small, but reliable, effect of initial rate setting $(\mathrm{p}<.05)$. Of the 16 subjects, 3 $(\mathbf{1 8 . 8 \%})$ reported some driving. This result, also, was very reliably different from the reports of driving in Experiment $1\left[\chi^{2}(1)=13.71, p=.0002\right]$.

\section{DISCUSSION}

The effect of surround luminance was very consistent throughout all three experiments. Before discussing this novel finding in more detail, let us first consider some points of similarity and difference between our results and those of previous studies which dealt with similar variables.

One would guess intuitively that, at very low rates, the task of matching tonebursts to flashes would become quite accurate. Figure 1 shows that this is just what seemed to happen. At $10 \mathrm{~Hz}$, matches may deviate greatly from a veridical match, but at progressively lower rates, all curves appear to be converging toward a veridical rate match. The same trend can be observed in the data of Nelson, Bartley, and Bochniak (1965) and also in the results reported by Mackavey (1966), who had subjects match one intermittent visual stimulus by varying a second one. Deviations from a veridical match seem to become pronounced only when the rate of the target stimulus reaches about $10 \mathrm{~Hz}$, and they become still more pronounced at higher rates (Mackavey, 1966).

On the other hand, the direction of the deviation from a veridical match appears to be a complex function of several variables. In Experiment 1, in which toneburst rate was adjusted to match that of a red LED, the matched toneburst rates were consistently higher than the target flashrate. However, in Experiment 2 , in which subjects varied the same red LED to match a fixed toneburst rate, the tone and flash rates were much more alike: biased in one direction from a veridical match when the surround was illuminated and biased in the other direction when it was extinguished. And, in Experiment 3, in which subjects adjusted a green LED to match fixed toneburst rates, the toneburst rates were consistently lower than the corresponding flash rates. Our overall results show that there can be marked disparities between the magnitude and direction of the difference between auditory and visual rates that appear matched, and this disparity can be a function of which stimulus the subject controls as well as of flash intensity. It is not completely clear whether flash hue had an effect independent of luminance, owing to the confounding of hue and luminance when comparing Experiment 3 with other conditions, nor can hue effects be readily isolated when comparing our results with the earlier research we have cited, all of which used white flash stimuli. For example, Nelson, Bartley, and Bochniak (1965) had subjects adjust a click to match the rate of a white flash stimulus $1 \mathrm{deg}$ in diameter in a wholly dark field. The matched auditory rates they reported were much lower than the visual rates being matched.

Nelson et al. also reported consistent effects of flash duty cycle, or light-to-dark ratio; small lightto-dark ratios caused the matching stimulus rate to be higher than did long light-to-dark ratios. Gebhard and Mowbray (1959) reported that, in pilot studies, duty cycle of either the light or sound was of little importance, though no experimental data on this were presented. The small and statistically nonsignificant results of this variable in Experiment 1 of the present study were actually in the opposite direction to that reported by Nelson, Bartley, and Bochniak (1965). Gebhard and Mowbray (1959) and Nelson et al. (1965) both used a white flash stimulus, whereas ours was red, but, in view of other procedural differences, it probably is fruitless to speculate at length about the cause of these conflicting reports of duty cycle effects.

Our results definitely confirm Gebhard and Mowbray's (1959) finding that flash rate seems to be "driven" by auditory rate when subjects control the auditory stimulus, but not when they control the visual one. It also is apparent that the visual and auditory rates that are judged to match are powerfully affected by which stimulus the subject adjusts. Yet, in many respects, this driving effect is rather mysterious. If auditory rates really drive visual ones, why is this not evident regardless of which modality the subject adjusts, and why is matching in both procedures not equally difficult? Gebhard and Mowbray (1959) did claim that matching behavior was more variable when subjects controlled the auditory rather than the visual stimulus, but the measures they presented were not actually measures of variability, so it is not clear that their data really support this claim. In our data, coefficients of variation did tend to be larger when subjects controlled the auditory stimulus, but this effect was short of statistical significance. One is left with the impression that any difference in the difficulty of these two matching procedures is much more evident in subjects' subjective reports than in objective measures of variability.

One variable in the present study which always produced effects in the same direction regardless of other procedural and stimulus variations was flash surround luminance. The toneburst rate corresponding to a given flash rate was always reduced when the surround was illuminated rather than dark.

An explanation for this effect is far from clear. One thing that seemingly can be ruled out as a major 
factor is photochemical visual adaptation, because the changes in apparent flash rate that occur with lighted vs. dark surrounds take place instantaneously when surround luminance is changed.

One possibility we considered is visual contrast effects. That is, if the lighted surround reduced the brightness of the flashing target by contrast, subjective rate might be affected in the same way that it would if the luminance of the flashing target itself were reduced. This interpretation is consistent with the flash luminance effects obtained in Experiment 1; that is, the higher flash luminance $\left(340 \mathrm{~cd} / \mathrm{m}^{2}\right) \mathrm{re}$ sulted in higher matched toneburst rates than did the lower luminance $\left(52 \mathrm{~cd} / \mathrm{m}^{2}\right)$, at least at the $10-\mathrm{Hz}$ rate, paralleling the higher toneburst matches obtained with dark than with lighted surround.

On the other hand, differences in surround luminance had substantial effects at 7 and $4 \mathrm{~Hz}$, whereas differences in flash luminance had relatively little effect at these lower rates. Also, the effects of flash luminance reported by other investigators have not always been consistent with the present results. Brown (1965, p. 293) drew the general conclusion that "[as] the luminance of a stimulus of constant frequency is increased, the flicker rate appears to decrease." Segal (1940) and Mackavey (1966) both reported that increases in flash luminance were accompanied by decreases in matching stimulus rate, but Nelson, Bartley, and Bochniak (1965), who varied flash luminance over a 10,000:1 range, found only very small and not too consistent effects of intensity. Gebhard and Mowbray (1959) claimed that variation in intensity of either the auditory or the visual stimulus was of little importance.

Another feature of our results that is not consistent with a visual contrast interpretation is that the 340 $\mathrm{cd} / \mathrm{m}^{2}$ flash luminance employed in Experiments 1 and 2 is substantially greater than the lighted surround luminance of $215 \mathrm{~cd} / \mathrm{m}^{2}$. The evidence from studies measuring brightness contrast in target-andsurround configurations is that little or no contrast is measurable until the surround luminance surpasses that of the central target (Diamond, 1953; Heinemann, 1955). But surround luminance effects in the present study occurred to about the same degree regardless of whether target luminance was greater or less than that of the surround. It seems unlikely, therefore, that our surround luminance effect is to be understood by analogy with brightness contrast.

There have been some studies of the effect of surround luminance on critical flicker fusion frequency (CFF), and insofar as variables affecting CFF may have predictable effects on the appearance of subfusion flash rates, it is interesting to compare these results with the present experiments. A CFF study by Foley (1956), using a flashing white glow modulator tube and white surround, came closest to approximating the conditions of the present study. Lighted vs. dark surround increased CFF by as much as about $17 \%$. Berger (1954) also generally found that CFF was increased by lighted vs. dark surrounds. These changes in CFF are opposite in direction to the changes produced in matching rates to subfusion stimuli in the present study.

When an auditory-visual rate match departs from a veridical match, it is impossible to state whether one stimulus is "correctly" perceived while the apparent rate of the other is "illusory," or vice versa. The evidence suggests, however, that in settings like ours, it is mainly visual rate that is plastic and departs from veridical. The present study, Segal (1940), and Mackavey (1966) all found that the match to a flashing light could be varied significantly by changes in the luminance of the flash, other factors being constant. But Gebhard and Mowbray (1959) reported that changes in the intensity and duty cycle of the auditory stimulus had little effect on rate matching, an observation also made during pilot work in our laboratory. And there is little question that the effect of surround luminance on apparent flash rate is a visual system effect; it was easily observed by several of our subjects when viewing the flashes in light vs. dark surrounds in the complete absence of the auditory stimulus.

An interesting operation which might give clues to the central vs. peripheral locus of the surround luminance effect would be to provide dichoptic presentation of the flashing target and its surround. We intend to test this operation in future work.

\section{REFERENCES}

BERGER, C. Illumination of surrounding field and flicker fusion frequency with foveal images of different sizes. Acta Physiologica Scandinavica, 1954, 30, 160-170.

Brown, J. L. Flicker and intermittent stimulation. In C. $\mathbf{H}$. Graham (Ed.), Vision and visual perception. New York: Wiley, 1965.

Diamond, A. L. Foveal simultaneous brightness contrast as a function of inducing- and test-field luminances. Journal of Experimental Psychology, 1953, 45, 304-314.

Foley, P. J. Effect of background on the critical flicker frequency. Canadian Journal of Psychology, 1956, 10, 200-206.

Forsyth, D. M., \& Chapanis, A. Counting repeated light flashes as a function of their number, their rate of presentation, and retinal location stimulated. Journal of Experimental Psychology, 1958, 56, 385-391.

Garner, W. R. The accuracy of counting repeated short tones. Journal of Experimental Psychology, 1951, 41, 310-316.

Gebhard, J. W., \& MowBray, G. H. On discriminating the rate of visual flicker and auditory flutter. American Journal of Psychology, 1959, 72, 521-529.

Heinemann, E. G. Simultaneous brightness induction as a function of inducing- and test-field luminances. Journal of Experimental Psychology, 1955, 50, 89-96.

Huntsberger, D. V. Elements of statistical inference. Boston: Allyn \& Bacon, 1967.

LECHELT, E. C. Temporal numerosity discrimination: Intermodal comparisons revisited. British Journal of Psychology, 1975, 66, 101-108.

MaCkAVEY, W. R. Effect of pulse rate and intensity upon visual 
flash rate. Journal of Experimental Psychology, 1966, 72, 528-531.

Massaro, D. W. Perceiving and counting sounds. Journal of Experimental Psychology: Human Perception and Performance, $1976,2,337-346$.

Nelson, T. M., Bartley, S. H., \& Bochniak, F. Flash frequency when brightness is varied by manipulation of the temporal distribution of photic intermittency. Journal of Psychology, 1965, 59, 195-205.

Pollack, I. Auditory flutter. American Journal of Psychology, $1952,65,544-554$.

Segal, J. Le mécanisme de la vision en lumière intermittente. Paris: Alcan, 1940.

Springen, R. M., Deutsch, J. A., \& Stanley, G. Double flashes from single pulses of light. Perception \& Psychophysics, 1975, 18, 398-400.

Stevens, J. C., \& Shickman, G. M. The perception of repetition rate. Journal of Experimental Psychology, 1959, 58, 433-440.

Taubman, R. E. Studies in judged number: I. The judgment of auditory number. Journal of General Psychology, 1950, 43, 167-194. (a)

Taubman, R. E. Studies in judged number: II. The judgment of visual number. Journal of General Psychology, 1950, 43, 195219. (b)
White, C. T., \& Cheatham, P. G. Temporal numerosity: IV. A comparison of the major senses. Journal of Experimental Psychology, 1959, 58, 441-444.

\section{NOTE}

1. This condition also produced substantial heterogeneity of variance in the ANOVAs. Therefore, all the analyses were redone with the data transformed to the logarithms of the original rate scores. The results of these analyses were essentially identical to those reported here except for the interaction between stimulus rate and surround luminance found in Experiment 2. This interaction, significant at the $5 \%$ level in the analysis of original measures, did not approach significance in the log-transformed data. This undoubtedly occurred because the ratio of surround-off to surround-on match scores remained approximately constant at different stimulus rates in Experiment 2. This would produce a Surround by Rate interaction in the original measures, but not in log-transformed ones.

(Manuscript received December 16, 1980; accepted for publication April 14, 1981.) 